\title{
Iodine Sorption Value and Surface Chemical Analysis of Regenerated Cellulosic Fibres
}

\author{
Liberato Venant Haule \\ College of Engineering and Technology, University of Dar es Salaam, Dar es Salaam, Tanzania \\ Email: liberato.haule@udsm.ac.tz
}

Received 6 April 2016; accepted 15 May 2016; published 18 May 2016

Copyright (C 2016 by author and Scientific Research Publishing Inc.

This work is licensed under the Creative Commons Attribution International License (CC BY). http://creativecommons.org/licenses/by/4.0/

(c) (i) Open Access

\section{Abstract}

The surface chemical analysis and bulk analysis were conducted for fibres regenerated from waste garments and treated with iodine solution. The aim was to assess the fibre accessibility by the iodine solution and ascertain the location of the reagent within the fibres. X-ray Photoelectron Spectroscopy (XPS) analysis indicated that the fibres regenerated from indigo dyed waste denim garments (ReCell-Denim) had a relatively high accessibility by the iodine solution compared to the standard lyocell, ReCell-1 and ReCell-2 fibres. With the exception of ReCell-Denim, the standard lyocell, ReCell-1 and ReCell-2 fibre's iodine sorption values correlated well with the percentage crystallinity. The high accessibility of the ReCell-Denim fibres was attributed to the presence of the positively charged nitrogen from the indigo dyes that improved the substantivity of the fibres to the iodine solution. The iodine sorption of the fibres is relatively higher in the bulk compared to the fibre surface.

\section{Keywords}

Iodine Sorption Value, XPS, Bulk Analysis, Cellulose, Waste Garments

\section{Introduction}

Traditionally man-made cellulose fibres are produced from regenerated cellulose II by treatment of native cellulose such as high purity wood pulp with strong sodium hydroxide or physical dissolution [1]. The fibres regenerated by treatment of the pulp with strong sodium hydroxide solution are generically known as viscose fibres whereas the fibres regenerated by the solvent dissolution are generically known as lyocell fibres [1]. Lyocell fibres are commercially regenerated by the dissolution of the high purity pulp in an $\mathrm{N}$-methyl $\mathrm{N}$-morpholine oxide (NMMO) solution and subsequent extrusion and regeneration of the fibres. The lyocell process is preferred due to less consumption of water, less toxicity and $100 \%$ potential recovery of the solvent during the fibre making 
process.

Although all regenerate fibres exhibit the cellulose II unit cell, the properties of the fibres above molecular level depend other factors such as the spinning conditions, [2], with density, crystallite size, crystallite orientation and pore structure of the fibres varying. Accessibility by reagents was among the properties reported to vary with the treatment history of the feed stock for fibres regenerated from cotton waste garments using the NMMO solution [3].

The accessibility of the fibres is important because it provides information on how the fibres respond to the reagents during wet processing such as dyeing. Empirically the fibre accessibility by reagents is determined by the Iodine Sorption Value (ISV) test. According to Nelson, [4] [5], the ISV test was first developed for the determination of effectiveness of mercerization process. The test were later modified and considered as an empirical test for the investigation of the structure of both natural and regenerated fibres during fibre growth [6] and regeneration processes [7], respectively. The ISV test provides an empirical estimation of the accessibility of cellulose fibres by various reagents such as dyes [4] [5]. During wet processing of cellulose fibres, the chemical reagents modify the fibre's structure by accessing the amorphous fraction of the substrates.

The ISV test results are affected by the test temperature, duration of equilibria, the degree of agitation, reagent concentration and the method for measuring the iodine adsorbed, [5] [8], thus the data reproducibility is always not acceptable [4] [5]. If the temperature is not well controlled during the test, the ISV results may vary by up to $5 \%$, therefore it is important to ensure constant temperature and the ISV data should specify the temperature under which adsorption occurred [8]. Despite the existing weaknesses in terms of reproducibility of the results the ISV has widely been applied on the determination of accessibility of cellulosic fibres by number of researchers [4] [5] [9]-[11]. The ISV test results were used to determine the crystallinity index of the cellulose fibres as one way of monitoring of the changes of supermolecular structure of the fibres [4] [7] [9] [10]. The iodine sorption test was also used with other techniques to investigate the relationship between sorption and accessibility properties of lyocell, viscose and modal fibres. The results indicated that repetitive washing and drying affected the pore size and pore size distribution of the cellulose fibres and its accessibility/sorption properties [11]. Structural change of cellulose fibres is more sensitive to ISV than other accessibility tests such as water retention and water sorption tests [4] [11]. Further studies suggested that water sorption and retention power could only be used as a measure of swelling ability and the accessibility of fibres to aqueous baths during wet finishing processes whereas iodine sorption is a measure of the accessibility of the fibres and of crystallinity index [10]. However the use of cellulose accessibility through the use of various reagents as a method to estimate crystallinity of cellulose has been regarded as contentious [9]. This is due to the fact that the different reagents used to determine crystallinity of fibres brought different results for the same type of fibres [12]. For instance when the adsorbed iodine is above $11 \%$ on weight of cellulose, the iodine solution tends to penetrate the crystalline regions [4]. This suggests that under certain conditions the iodine solution would access both crystalline and non-crystalline components of the cellulose polymer.

The ISV test has also been used to observe accessibility of polyester fibres following heat setting, the results indicated that as the heat setting increases, the fibres will have less sites accessed by the iodine. However if the iodine sorption test is conducted at increasing temperatures the sorption increases, due to the temperature "opening" the fibre structure and increasing the iodine diffusion into the fibre structure [13].

While previous research has concentrated on the optimization of the sorption conditions, no study has focused on optimizing the determination of the iodine adsorbed by cellulose. It is the aim of this study to investigate the ISV of selected regenerate fibres and the location of the adsorbed iodine.

X-ray Photoelectron Spectroscopy (XPS) is an analytical technique which is used to study the surface chemical composition of solids. With XPS, the sample is bombarded by X-ray beam in an evacuated chamber. The $\mathrm{X}$-ray beam interacts with the substrate's atoms, causes excitation and escape of electrons from the surface of the specimen; the electrons are collected depending on the atomic binding energies. The electrons escape from those atoms which are within the outer $10 \mathrm{~nm}$ of the surface of the specimen and the binding energy of the ejected photoelectron is influenced by chemical environment and oxidation state. In addition to providing qualitative information from the photoelectron binding energy, quantitative information can be obtained from the spectral intensity which provides atomic composition of the solids.

XPS is commonly used in surface chemical analysis of textile substrates. For instance XPS was used to determine the location of the flame retardants, soil repellence and easy care finishes following application of the finishes on the cotton fabrics and the results indicated that in order to understand the effectiveness of the appli- 
cation of the finishes, it is necessary to determine both surface and bulk analysis of the treated fabrics due to the fact that some of the finishes reacts in both the surface and bulk of the substrates [14].

XPS was used to probe surface changes of the cotton substrates which were plasma treated and chemically modified with flame retardants [15]. XPS was also used to investigate the wash durability of an easy care finished cotton fabrics whereby the stability of the methylol-based easy care finishes on different wash programmes was determined. By the use of XPS it was possible to determine the type of crosslinking between the easy care finish and the cotton fabrics in relation to the crease recovery angle performance [16]. Other applications of the XPS in textiles include assessment of the stripping of the easy care finishes from cotton fabrics in order to reclaim cotton fibres for regeneration of new fibres [3] [17]. In such treatments the effectiveness of removal of nitrogen containing easy care finish was assessed by monitoring of the $\mathrm{N}(1 \mathrm{~s})$ atoms on the surface of stripped cotton fabrics. The stripping of polycarboxylic acid easy care finish was monitored by the $-\mathrm{C}(1 \mathrm{~s})$ peak intensity assigned to the $-\mathrm{CO}_{2} \mathrm{H}$ or $-\mathrm{CO}_{2}$-Cell. XPS was also used to characterise the effectiveness of sisal fibre modification by silane in order to improve fibre compatibility with the matrix during composite making [18].

This paper investigated the surface chemical composition of the fibres regenerated from cotton waste garments and determines the accessibility of the fibres by reagent by the use of ISV. Furthermore the location of the reagent in the fibres is quantified by the XPS and bulk analysis of the Iodine treated fibres.

\section{Experimental}

\subsection{Dissolution and Spinning of Fibres}

The purification, dissolution of the pulp and spinning of fibres were done based on the previously reported work [3] where in order to spin fibres the required spinning dope was prepared by mixing $300 \mathrm{~g}$ of $50 \%$ NMMO solution with $27 \mathrm{~g}$ pulp and $0.2 \mathrm{~g}$ n-propyl gallate using a laboratory scale mixer. The dissolution process was made possible by mixing the pulp and NMMO solution at increasing temperature and vacuum at suitable steps until the final spinning dope was composed of $9 \%$ cellulose, $13 \%$ water and $78 \%$ NMMO. For every sample the dissolution dope was checked for fibre solubility using a light microscope. The fibres were then spun from a laboratory scale spinning machine at Lenzing AG, Austria. The spinneret used had 19 holes of $100 \mu \mathrm{m}$ in size and the spinning temperature was $115^{\circ} \mathrm{C}$. The dope throughput was $0.03 \mathrm{~g} / \mathrm{min}$ per hole, the air gap conditions were set at $30 \mathrm{~mm}, 24^{\circ} \mathrm{C}$ and $53 \%$ relative humidity. The winding speed was $25.1 \mathrm{~m} / \mathrm{min}$. and water was used to precipitate the fibres. The fibres were then oven dried at $60^{\circ} \mathrm{C}$ overnight prior to further analysis. The source and properties of the feedstock use for fibre making is presented in Table 1.

\subsection{Determination of the ISV}

The ISV of the ReCell fibres and Lyocell fibres was determined in accordance to method described by Nelson [5]. A $0.3 \mathrm{~g}$ specimen was placed in tared $250 \mathrm{~mL}$, glass stoppered Erlenmeyer flask and weight of flask and contents was recorded. A volume of $2 \mathrm{~mL}$ concentrated iodine solution (which was prepared from $5 \mathrm{~g}$ Iodine, 40 g potassium iodide and $50 \mathrm{~mL}$ water) was added on the sample. The mixture was then mixed with a glass rod and the weight of the flask plus fibres plus iodine solution was recorded. After mixing the specimen with iodine, the mixture was allowed to stand for 3 minutes in order to reach sorption equilibrium between the fibres and concentrated iodine solution.

At the end of sorption equilibrium, $100 \mathrm{~mL}$ of saturated sodium sulphate solution ( $200 \mathrm{~g} / \mathrm{L}$ ) was added into the flask containing the fibres and iodine solution. Part of the sodium sulphate solution was used to rinse the glass rod which was used to mix the fibres with concentrated iodine solution. Then the system was stirred using

Table 1. Source and properties of the feed stock used for fibre making.

\begin{tabular}{cccc}
\hline S/No. & Source & Purification approach & Fibre name \\
1 & Cotton fabric & Washed 50 times using detergent, Ground into pulp & ReCell-1 \\
2 & Cotton fabrics & $\begin{array}{c}\text { Treated with easy care finish, washed } 50 \text { times stripped in } \\
\text { acid-alkali solution blend with } 80 \% \text { high purity wood pulp }\end{array}$ & Washed and ground into pulp \\
3 & Waste denim garments & Chemical treated pulp & ReCell-Denim \\
\hline
\end{tabular}


mechanical shaker for one hour at $23^{\circ} \mathrm{C} \pm 1^{\circ} \mathrm{C}$. The saturated solution of sodium sulphate was added in order to remove any excess iodine which was not bound to the specimen. After addition of the saturated solution of sodium sulphate the mixture was shaken on mechanical shaker for one hour to ensure complete desorption of the excess iodine. A blank solution was prepared by similar procedure omitting the sample. After one hour of the shaking of the mixture, the solution was filtered using tared coarse-frit glass crucible. The aliquot amount of sample and blank solution were titrated with $0.02 \mathrm{~N}$ sodium thiosulphate solution. The sample was then washed on tared crucible thoroughly with deionised water, dried in crucible at $105^{\circ} \mathrm{C}$ for 4 hours and finally the crucible was allowed to cool under phosphorus pentoxide and weighed to obtain the final mass of the fibres. The ISV ( $\mathrm{mgI}_{2} / \mathrm{g}$ cellulose) was calculated according to the Equation (1)

$$
I S V=126.91 \times N \times F \times \frac{T_{s}-t_{s}}{w} .
$$

where $T_{s}=T_{b} \times I_{s} / I_{b}$ is the $\mathrm{mL}$ sodium thiosulphate solution equivalent to initial iodine in aliquot of sample solution; $I_{s}$ is the weight of concentrated iodine-potassium iodide solution in sample solution; $I_{b}$ is the weight of the concentrated iodine-potassium iodide solution in blank solution; $T_{b}$ is the $\mathrm{mL}$ sodium thiosulphate solution for aliquot blank; $t_{s}$ is $\mathrm{mL}$ sodium thiosulphate solution for aliquot of supernatant filtered from sample; $F$ is aliquot factor (total volume is $102 \mathrm{~mL}$; W, oven dry weight of sample in grams. Three replicates were conducted for each type of fibre and the mean reported.

Samples for XPS and bulk analysis were treated parallel to the ISV test but after adsorption/desorption of the iodine the samples were cold rinsed and air dried.

\subsection{XPS Analysis}

XPS analysis was performed using a Kratos Axis system spectrometer. The fibre bundles sample were cut from the middle of the specimen and attached to the sample holder using double sided tape. Monochromatic AlK ${ }_{\alpha}$ $\mathrm{X}$-rays $(1486.69 \mathrm{eV})$ with a power of $150 \mathrm{~W}$ were used to irradiate the samples. A wide scan spectrum was recorded with pass energy of $160 \mathrm{eV}$ from which the surface composition (C, I, N and O) was determined. High resolution Carbon (1s) spectra were recorded with pass energy of $40 \mathrm{eV}$. The binding energy (BE) values were calculated relative to the Carbon (1s) photoelectron at $285.0 \mathrm{eV}$. Charge compensation for the samples was achieved using a 4 - $7 \mathrm{eV}$ electron beam at a flood current of approximately $0.1 \mathrm{~mA}$, and an electrically ground $90 \%$ transmission nickel mesh screen adjacent to the fibre samples. Data analysis was performed using the CASA XPS software [19].

\subsection{Elemental Bulk Analysis}

Elemental analyses were performed by using a Carlo Erba instrument EA1108 Elemental Analyser. The error associated to the measurement is $\pm 0.04 \%$.

\subsection{Wide Angle X-Ray Diffraction (WAXD) Fibre Analysis}

The crystallinity of the fibres were determined from the WAXD analysis as previously explained [20] and described here under;

The Xpert Phillips (Power $45 \mathrm{kV}$ and current $40 \mathrm{~mA}$ ) instrument with a copper anode with an X-ray wavelength of $1.54060 \AA$ was used for WAXD analysis. Scans were recorded from $1^{\circ}$ to $30^{\circ} 2 \theta$ with a step size of 0.07 with both equatorial scans acquired for aligned fibres, taking the meridional axis as the orientation reference.

In order to account for the instrument broadening contribution to the experimental peak width, the same experiment geometry was applied to a powdered silicon standard with the (111) reflection at $28.40^{\circ}(2 \theta)$. The crystallinity of the fibres regenerated from cotton based waste garments and lyocell fibres were determined from the wide-angle X-ray diffraction patterns recorded perpendicular to the fibres axis. The percentage of crystalline material was calculated by the first determination of the peak height of the diffractograms at the position of the (002) plane at $2 \theta=21.7^{\circ}\left(\mathrm{I}_{002}\right)$ and the peak height of the amorphous background at $2 \theta=16^{\circ}\left(\mathrm{I}_{\mathrm{am}}\right)$ and crystallinity was calculated as Equation (2). 


$$
\text { crystallinity }=\frac{I_{002}-I_{a m}}{I_{002}} \times 100
$$

The WAXD crystallinity were compared to both XP and bulk iodine sorption values.

\section{Results and Discussion}

Examination of the wide scan surface elemental analysis of the iodine free ReCell and Lyocell fibres indicated that the surface of the fibres is rich in C and $\mathrm{O}$ and the XPS analysis of the ReCell-Denim fibres indicated some surface nitrogen, Table 2, which can be assigned to residual indigo dye present in the fibres. The high resolution C1(s) spectra of the ReCell and Lyocell fibres indicated that the major spectral species occurred at $285.0 \mathrm{eV}$, which was due to $\mathrm{C}-\mathrm{C}$ and $\mathrm{C}-\mathrm{H}$ bonding species, indicating that the surface was not pure cellulose, Figure 1. The nature of these impurities was not ascertained but some of it may be due to the purification of the feed stock, dissolution and regeneration solvents.

The nature of chemical species occurring at $285.0 \mathrm{eV}$ for natural cellulose has been previously investigated and reported somewhere else [14] [16] [21] [22]. Re-examination of Table 2 indicated that the C(1s) peak intensity ratio of $286.6 \mathrm{eV}(\mathrm{C}-\mathrm{O})$ to $288.0 \mathrm{eV}$ (C=O, O-C-O) was highest for lyocell fibres (5:1 ratio) and lowest for ReCell-Denim fibres (2.4:1 ratio). The ReCell-1 fibres indicated a relative spectra intensity ratio which is within the minimum theoretical range. The relative spectral peak intensity for ReCell-2 was $28 \%$ below the theoretical minimum and the reason for such deviation may be due to the contaminations arising during the purification of the feedstock, dissolution and regeneration solvents. Theoretically the relative spectral intensity for the C1(s), BE $286.6 \mathrm{eV}$ to BE $288 \mathrm{eV}$ is supposed to be 5:1 ( $\pm 10 \%)$. The lower peak intensity ratio for ReCell-Denim fibres was probably due to the residual indigo dye present in the fibres and this is further confirmed by the extraordinary ISV of the ReCell-Denim fibres. It was anticipated that the ReCell-Denim fibres could have exhibited the lowest $286.6 \mathrm{eV}(\mathrm{C}-\mathrm{O})$ to $288.0 \mathrm{eV}(\mathrm{C}=\mathrm{O}, \mathrm{O}-\mathrm{C}-\mathrm{O})$ spectral peak intensity due to the residual indigo dye present in the fibres; but the ReCell-2 fibres exhibited the lowest relative spectral peak intensity and the reason for such deviation is uncertain.

Table 3 shows the surface and bulk iodine content of the ReCell fibres treated in concentrated iodine solution and the WAXD crystallinity of the untreated fibres. The crystallinity of the fibres increases in the order of lyocell, ReCell-2, ReCell-1 and ReCell-Denim. The ISV for the fibres was expected to decrease as the crystallinity of the fibres increases but the ReCell-Denim was anomalous.

Table 2. XP wide scan elemental atomic composition and $\mathrm{C} 1(\mathrm{~s}) \mathrm{BE}=286.6 / \mathrm{BE}=288.0 \mathrm{eV}$ intensity ratio for lyocell and ReCell fibres.

\begin{tabular}{|c|c|c|c|c|c|c|}
\hline \multirow{2}{*}{ Fibre } & \multicolumn{3}{|c|}{ Wide Scan, atomic \% } & \multicolumn{3}{|c|}{ C1(s) high resolution component intensity } \\
\hline & $\mathrm{C}$ & $\mathrm{O}$ & $\mathrm{N}$ & $\mathrm{C}-\mathrm{O}$ & $\mathrm{C}=\mathrm{O}$ & $\mathrm{C}-\mathrm{O} / \mathrm{C}=\mathrm{O}$ \\
\hline Lyocell & 76.0 & 24.0 & 0.0 & 27.4 & 5.4 & 5.1 \\
\hline ReCell-1 & 72.9 & 27.1 & 0.0 & 34.3 & 7.9 & 4.3 \\
\hline ReCell-Denim & 71.5 & 28.0 & 0.5 & 32.7 & 13.6 & 2.4 \\
\hline ReCell-2 & 76.0 & 24.0 & 0.0 & 32.5 & 9.0 & 3.6 \\
\hline
\end{tabular}

Table 3. XP I(3d) surface and iodine bulk atomic composition for ReCell fibres treated with iodine solution.

\begin{tabular}{cccc}
\hline Fibre type & WAXD Crystallinity $\%$ & Surface iodine content, \% atomic & Bulk iodine content, \% atomic \\
\hline Lyocell & 79.6 & 1.0 & 13.0 \\
ReCell-1 & 86.6 & 0.5 & 8.6 \\
ReCell-Denim & 87.1 & 1.0 & 11.2 \\
ReCell-2 & 81.7 & 0.8 & 8.0 \\
\hline
\end{tabular}




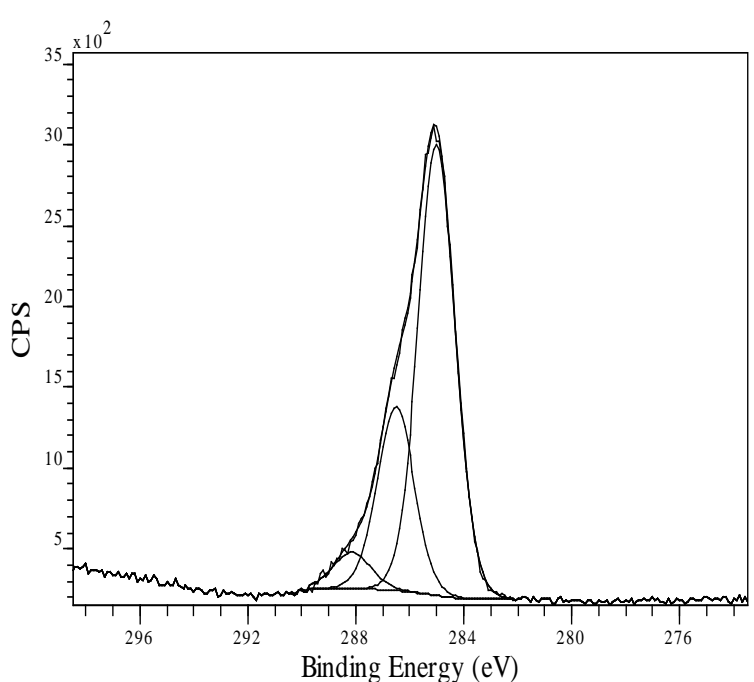

(a)

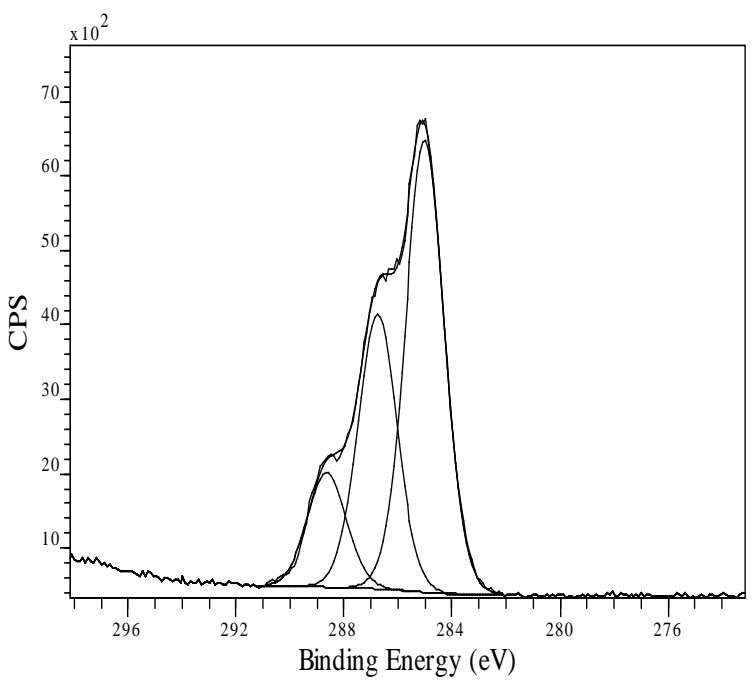

(c)

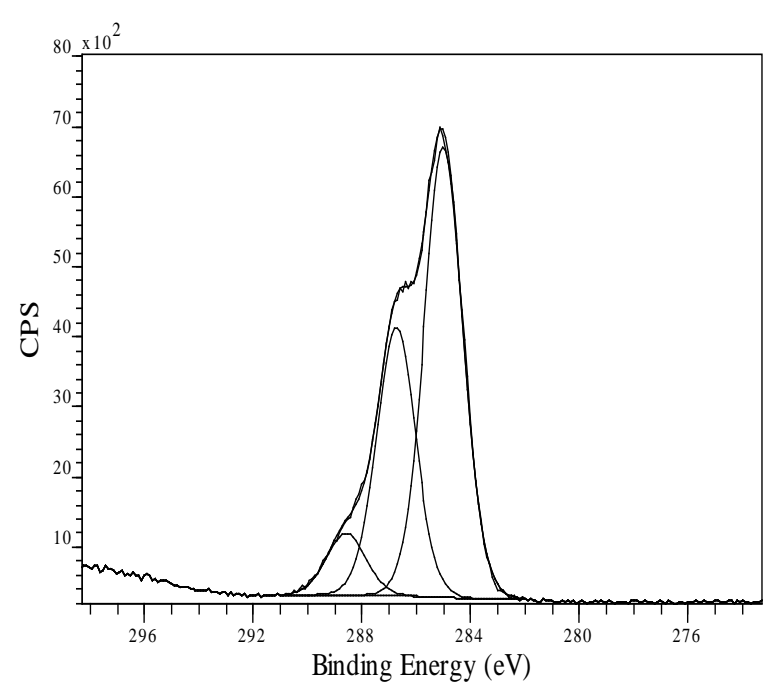

(b)

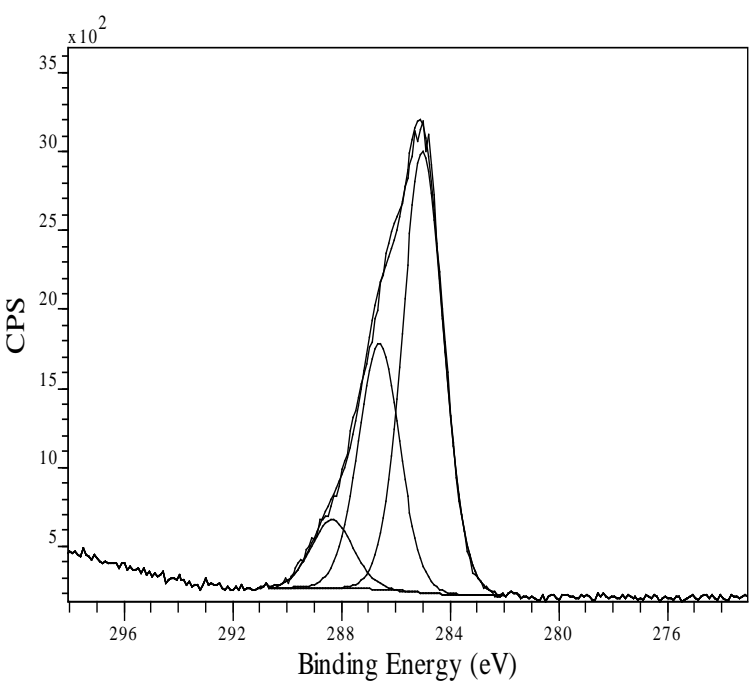

(d)

Figure 1. C(1s) XP spectra of (a) Lyocell, (b) ReCell-1, (c) ReCell-Denim and (d) ReCell-2 fibres.

The results indicated that the bulk of the fibres adsorb more iodine than the surface and this supports the argument that under certain conditions the iodine sorption penetrates into the crystalline component of the cellulose [4]. The ReCell-1 fibres have the lowest surface adsorption of iodine followed by ReCell-2, ReCell-Denim and lyocell fibres. The lower surface iodine adsorption by ReCell compared to standard lyocell fibres was related to the relatively higher crystalline fraction in the former and this agrees with the previously reported findings [20]. However, despite the highest crystallinity, the ReCell-Denim exhibited higher surface iodine content than the ReCell-1 and ReCell-2 fibres, and can be explained as follows. During treatment of the fibres with iodine solution, the iodine $\left(I_{2}\right)$ reacts with the iodide $(I)$ to form a highly soluble tri-iodide ion. In order to maintain the concentration of the iodine in the solution there is always an excess of $I$ ion which with the tri-iodide ion, was adsorbed by the cellulose. The adsorption of the iodide ion is via the partially positive hydrogen atoms of the cellulose polar hydroxyl groups. The ReCell-Denim fibres also contain indigo dye which possesses partially positive charges, thus enhancing the adsorption of the iodine by the fibres. This explains the relatively high ISV of ReCell-Denim fibres relative to ReCell-1 and ReCell-2 fibres.

Blending of wood and waste cotton pulp resulted in an enriched cellulose surface thus producing an increase in the adsorption of iodine at the surface and explains why the iodine content for the ReCell-2 fibres was higher 
than ReCell-1 but lower than lyocell fibres. The bulk iodine content of the lyocell, ReCell-1 and ReCell-Denim followed the same trend as for surface XP iodine. However the exception was observed for ReCell-2 fibres with the bulk iodine content below the ReCell-1 and lyocell fibres, the reason for this behaviour is uncertain at present.

Examination of the C1(s) spectra of the fibres treated in iodine solution indicated an increase in the spectral peak intensity at $289.0 \mathrm{eV}$, Figure 2. The formation of peak associated with carboxylic acid species may be due to degradation of the fibres in acidic treatment bath or oxidation.

\section{Conclusions}

The surface chemical analysis and bulk analysis was conducted for fibres regenerated from waste garments and treated with iodine solution. The aim was to assess the fibre accessibility by the ISV and ascertain the location of the reagent within the fibres. XPS and bulk elemental analyses indicated that the fibres regenerated from waste denim without stripping off the indigo dye (ReCell-Denim) had a relatively high accessibility to the iodine solution compared to Lyocell, ReCell-1 and ReCell-2 fibres. The iodine sorption values of the investigated

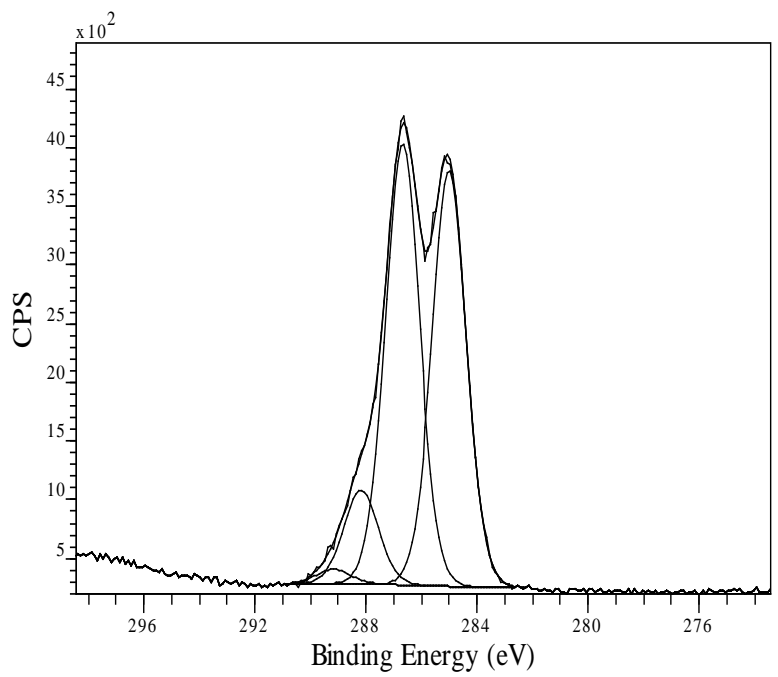

(a)

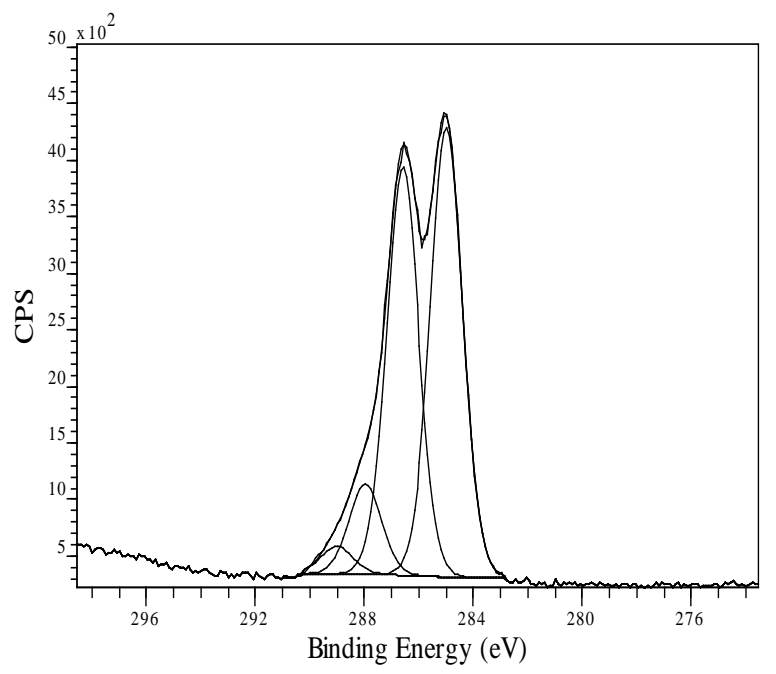

(c)

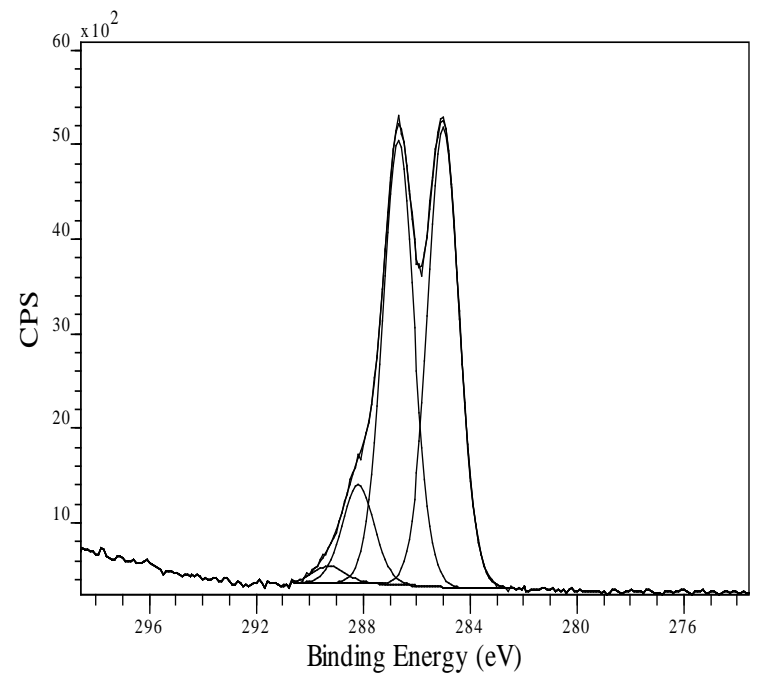

(b)

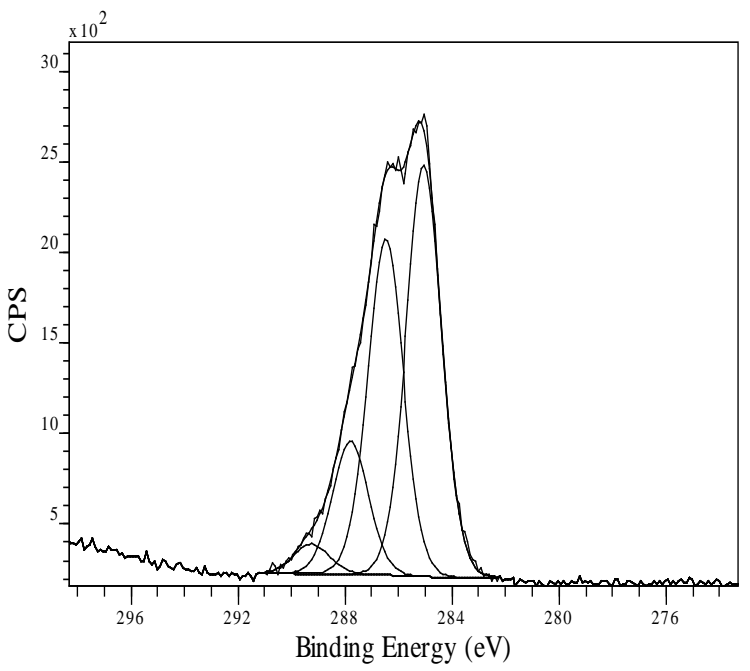

(d)

Figure 2. C(1s) XP spectra of (a) Lyocell, (b) ReCell-1, (c) ReCell-Denim and (d) ReCell-2 fibres after treatment in iodine solution. 
fibres were generally increasing as the decrease in WAXD crystallinity. The high accessibility of the ReCellDenim fibres was attributed by the presence of the positively nitrogen from the indigo dyes that improved the ability of the fibres to attract the negatively charged iodine.

Both XPS and iodine bulk analysis demonstrated that the iodine solution was mainly contained in the bulk of the fibres. The results suggest that more study may be conducted on the possible use of XPS or elemental analyses for the determination of the iodine sorption value of cellulose fibres instead of the titration technique.

\section{Acknowledgements}

The author recognises the financial sponsorship from the Tanzanian Gatsby Trust, the technical support of Lenzing, Austria and technical guidance of Chris Carr and Muriel Rigout.

\section{References}

[1] Klemm, D., Heublein, B., Fink, H.P. and Bohn, A. (2005) Cellulose: Fascinating Biopolymer and Sustainable Raw Material. Angewandte Chemie International Edition, 44, 3358-3393. http://dx.doi.org/10.1002/anie.200460587

[2] Fink, H.P., Weigel, P. and Purz, H.J. (2001) Structure Formation of Regenerated Cellulose Materials from NMMOSolutions. Progress in Polymer Science, 26, 1473-1524. http://dx.doi.org/10.1016/S0079-6700(01)00025-9

[3] Haule, L.V., Carr, C.M. and Rigout, M. (2016) Preparation and Physical Properties of Regenerated Cellulose Fibres from Cotton Waste Garments. Journal of Cleaner Production, 112, 4445-4451. http://dx.doi.org/10.1016/j.jclepro.2015.08.086

[4] Nelson, M.L. and Mares, T. (1965) Accessibility and Lateral Order Distribution of the Cellulose in the Developing Cotton Fiber1. Textile Research Journal, 35, 592-603. http://dx.doi.org/10.1016/j.jclepro.2015.08.086

[5] Nelson, M.L., Rousselle, M.A., Cangemi, S.J and Trouard, P. (1970) The Iodine Sorption Test. Factors Affecting Reproducibility and a Semimicro Adaptation. Textile Research Journal, 40, 872-880. http://dx.doi.org/10.1177/004051757004001002

[6] Rousselle, M.A. and Nelson, M.L. (1971) Accessibility of Cotton Cellulose by Deuterium Exchange. Textile Research Journal, 41, 599-604. http://dx.doi.org/10.1177/004051757104100708

[7] Doppert, H.L. (1967) Adsorption of Iodine from Aqueous Solutions by Samples of Tire Yarn from Regenerated Cellulose. Journal of Polymer Science Part A-2: Polymer Physics, 5, 263-270. http://dx.doi.org/10.1002/pol.1967.160050202

[8] Chitale, A.G. (1955) The Effect of Temperature on the Adsorption of Iodine by Cellulose. Textile Research Journal, 25, 886-887. http://dx.doi.org/10.1177/004051755502501008

[9] Hessler, L.E. and Power, R.E. (1954) The Use of Iodine Adsorption as a Measure of Cellulose Fiber Crystallinity. Textile Research Journal, 24, 822-827. http://dx.doi.org/10.1177/004051755402400906

[10] Praskalo, J., et al. (2009) Sorption Properties of TEMPO-Oxidized Natural and Man-Made Cellulose Fibers. Carbohydrate Polymers, 77, 791-798. http://dx.doi.org/10.1016/j.carbpol.2009.02.028

[11] Siroka, B., Noisternig, M., Griesser, U.J. and Bechtold, T. (2008) Characterization of Cellulosic Fibers and Fabrics by Sorption/Desorption. Carbohydrate Research, 343, 2194-2199. http://dx.doi.org/10.1016/j.carres.2008.01.037

[12] Ioelovich, M. and Alex Leykin, A. (2009) Accessibility and Supermolecular Structure of Cellulose. Cellulose Chemistry and Technology, 43, 379-385.

[13] Diéval, F., Mathieu, D. and Durand, B. (2001) Determining Polyester Fiber and Microfiber Structure by Iodine Sorption. Textile Research Journal, 71, 67-74.

[14] Soignet, D.M., Berni, R.J. and Benerito, R.R. (1976) Electron Spectroscopy for Chemical Analyses (ESCA)—A Tool for Studying Treated Textiles. Journal of Applied Polymer Science, 20, 2483-2495. http://dx.doi.org/10.1002/app.1976.070200917

[15] Benerito, R.R., Ward, T.L.D., Soignet, M. and Hinojosa, O. (1981) Modifications of Cotton Cellulose Surfaces by Use of Radiofrequency Cold Plasmas and Characterization of Surface Changes by ESCA. Textile Research Journal, 51, 224-232. http://dx.doi.org/10.1177/004051758105100402

[16] Haule, L.V., Rigout, M., Carr, C.M. and Jones, C.C. (2012) Surface and Bulk Chemical Analysis of the Durability of an Easy Care Finish on Cotton. Cellulose, 19, 1023-1030. http://dx.doi.org/10.1007/s10570-012-9672-x

[17] Haule, L.V., Carr, C.M. and Rigout, M. (2014) Investigation into the Removal of an Easy-Care Crosslinking Agent from Cotton and the Subsequent Regeneration of Lyocell-Type Fibres. Cellulose, 21, 2147-2156. http://dx.doi.org/10.1007/s10570-014-0225-3

[18] Gonzalez, D., Santos, V. and Paraja, J.C. (2012) Silane-Treated Lignocellulosic Fibers as Reinforcement Material in 
Polylactic Acid Biocomposites. Journal of Thermoplastic Composite Materials, 25, 1005-1022. http://dx.doi.org/10.1177/0892705711417029

[19] Walton, J., Wincott, P., Fairley, N. and Carrick, A. (2010) Peak Fitting with Casa XPS a Casa Pocket Book. Acolyte Science, Cheshire.

[20] Haule, L.V., Carr, C.M. and Rigout, M. (2016) Investigation into the Supramolecular Properties of Fibres Regenerated from Cotton Based Waste Garments. Carbohydrate Polymers, 144, 131-139. http://dx.doi.org/10.1016/j.carbpol.2016.02.054

[21] Mitchell, R., Carr, C.M., Parfitt, M., Vickerman, J. and Jones, C.C. (2005) Surface Chemical Analysis of Raw Cotton Fibres and Associated Materials. Cellulose, 12, 629-639. http://dx.doi.org/10.1007/s10570-005-9000-9

[22] Buchert, J., Pere, J., Johansson, L.S. and Campbell, J.M. (2001) Analysis of the Surface Chemistry of Linen and Cotton Fabrics. Textile Research Journal, 71, 626-629. http://dx.doi.org/10.1177/004051750107100710 